\title{
Reversal of cisplatin resistance by inhibiting PI3K/Akt signal pathway in human lung cancer cells
}

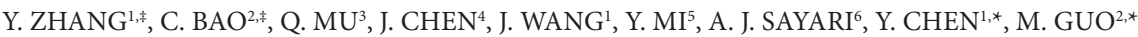 \\ ${ }^{1}$ Anhui medical university, School of Clinical medicine (174-hospital), Xiamen; ${ }^{2}$ Department of Thoracic And Cardiovascular Surgery, the 174th \\ Hospital of the Chinese People's Liberation Army, the Affiliated Chenggong Hospital of Xiamen University, Xiamen, China; ${ }^{3}$ Department of \\ Neurosurgery, Hongqi Hospital of Mudanjiang Medical University, Heilongjiang, China; ${ }^{4}$ The pharmacy college of Xiamen University, Xiamen, \\ China; ${ }^{5}$ Department of Thoracic Surgery, The First Affiliated Hospital of Xiamen University, Xiamen, China; ${ }^{6}$ University of Miami Miller School \\ of Medicine, Miami, FL, USA
}

*Correspondence: chenyq707@163.com, baochuanen@yahoo.com

Contributed equally to this work.

\section{Received August 6, 2015 / Accepted November 13, 2015}

\begin{abstract}
Cisplatin is regularly used in the treatment of lung cancer. However, its efficacy is limited because of drug resistance. In this study, we found that Akt expression and activity was increased in lung cancer cells with acquired cisplatin resistance (A549/DDP cells and H460/DDP cells) when compared to their parental cells. Inhibition of phosphatidylinositol 3-kinase (PI3K)/Akt kinase activity by its natural inhibitor, Wortmannin, could sensitize DDP-resistant cells to DDP and reverse DDP resistance. Combination treatment of Wortmannin with cisplatin is capable of increasing the mortality rate of both A549/DDP cells and H460/DDP cells. The present study also demonstrated that hyperactivation of PI3K/Aktpathway is closely associated with cisplatin resistance by regulating the Bax-mitochondria-mediated apoptosis pathway in human lung cancer. Inhibition of PI3K/Aktactivity in A549/DDP cells and H460/DDP cells could reverse cisplatin resistance by enhancing the effect of cisplatin on Bax oligomerization and release of Cytochrome $\mathrm{C}$, allowing activation of the caspasemediated apoptosis pathway. In conclusion, cisplatin resistance of lung cancer can be reversed via the inhibition of the PI3K/Akt signaling pathway. Therefore, both PI3K and Akt may be potential targets for overcoming cisplatin resistance in lung cancer.
\end{abstract}

Key words: wortmannin, lung cancer, cisplatin resistance, apoptosis

Lung cancer is still one of the major causes of death from cancer worldwide. Among the two classes of lung cancer, nonsmall cell lung cancer (NSCLC) and small cell lung cancer (SCLC), NSCLC accounts for approximately $90 \%$ of all lung cancers[1]. Compared to small cell carcinoma of the lung, NSCLC is any type of epithelial lung cancer exhibiting less sensitivity to chemotherapy. Furthermore, reports have shown that platinum-based chemotherapy is effective in treating lung cancer [2].Unfortunately, however, after a period of treatment, cisplatin-resistant lung cancer cells result in eventual chemotherapy failure [3].

To solve this vexing drug resistance problem, combination therapy has been the solution over the last two decades, owing to their synergistic effects seen in some trials[4-6]. Although drug resistance is a common phenomenon in chemotherapy, the puzzling mechanism involving complicated signaling pathways is not entirely clear. In order to avoid the effect of chemotherapeutics, tumor cells often elevate their expression level of several proteins, rendering themselves resistant to apoptosis.

The phosphatidylinositol 3-kinase (PI3K)/Akt pathway is one of the vital links between extracellular stimuli and fundamental cellular processes, playing a vital role in tumor cell proliferation, apoptosis, and survival [7]. Accumulating evidence has further confirmed that aberrant activation of PI3K and Akt contributes to drug resistance in many types of cancer, including lung cancer[8-10]. As a member of lipid kinase family, PI3K has been extensively researched for its importance in various signaling pathways [11]. PI3K is a heterodimer composed of two subunits, including a regulatory 
subunit and a catalytic subunit [12]. By phosphorylating the inositol ring 3 '-OH group in inositol phospholipids, $\mathrm{PI} 3 \mathrm{~K}$ acts as intracellular signal transducer enzyme able to generate the second messenger, phosphatidylinositol-3,4,5trisphosphate (PIP3). PIP3 plays a key role in recruiting $\mathrm{PH}$ domain-containing proteins, such as the serine/threonine kinases phosphoinositide-dependent kinase 1 (PDK1) and Akt (also known as PKB), to the plasma membrane. Owing to its broad spectrum of critical cellular functions, Akt is the vital signaling center for the growth and survival of the cell. Once correctly positioned at the membrane via binding of PIP3, Akt immediately interacts with these phospholipids, and is then phosphorylated by its activating kinases. Then, the activated Akt takes part in modulating the function of numerous substrates involved in regulating cell survival, cell cycle progression, and cellular growth. These substrates include mammalian target of rapamycin (mTOR) [13], nuclear factor kappa (NF- $\kappa \mathrm{B})$, apoptosis signal-regulating kinase1(ASK1) [14], cyclin-dependent kinases(CDKs), and $\mathrm{Bcl}-2 / \mathrm{Bcl}-\mathrm{X}$ [15]. Because of their special abilities in regulating cell survival, these previously mentioned proteins are notoriously related to chemotherapy resistance. Thus, as a regulator of multiple targets, PI3K/Akt has been attracting attention for its potential ability in reversing chemotherapy resistance[16-18].

The present study utilized Wortmannin, the inhibitor of PI3K, to investigate the reversibility of platinum-based chemotherapy resistance in NSCLC. Specifically, we examined the capability of Wortmannin in sensitizing the effects of cisplatin on the cisplatin-resistant strain of $\mathrm{H} 460$ cells (H460/DDP) and A549 cells (A549/DDP).

\section{Materials and methods}

Materials and cell culture. Wortmannin, cisplatin, and all chemicals for cell culture were purchased from Sigma-Aldrich (St. Louis, MO, USA). The antibodies anti-Akt, anti-phosphoAkt, anti-phospho-BAD, anti-BAD, anti-Bcl-2, anti-Bax, anti- Cytochrome C, Pro-caspase-3, Cleaved-caspase- 3 and anti- $\beta$-actin were purchased from Cell Signaling Technology (Beverly, MA, USA). The secondary antibodies, anti-mouse IgG and anti-rabbit IgG, were obtained from Santa Cruz Biotechnology Inc (Dallas, TX, USA). Human lung carcinoma cells (A549 cells and H460 cells) were obtained from the Beinuo biological technology co, LTD (Shanghai, china). The cells were maintained in the appropriate environment $\left(37^{\circ} \mathrm{C}\right.$, $5 \% \mathrm{CO}_{2}, 85 \%$ humidity) in RPMI- 1640 plus $1 \%$ glutamine and $10 \%$ fetal calf serum (Biochrom; Berlin, FRG).

Development of cisplatin-resistant variant cells. A549 cells and H460 cells were maintained in RPMI-1640 medium $\left(37^{\circ} \mathrm{C}, 10 \% \mathrm{CO}_{2}\right)$ supplemented with $10 \%$ fetal calf serum, $100 \mathrm{U} / \mathrm{ml}$ penicillin, and $100 \mathrm{mg} / \mathrm{ml}$ streptomycin. Development of cisplatin resistance in A549 and H460 cells were induced as follows: cells were continuously exposed to escalating cisplatin concentrations ranging from $3 \mathrm{nmol} / \mathrm{L}$ to $200 \mu \mathrm{mol} / \mathrm{L}$, over a 3-month period. Resistant cells were named A549/DDP and H460/DDP. The chemoresistant ability of A549/DDP and H460/DDP cells was assessed by MTT assay. Both cisplatin-sensitive parental cells and cisplatin- resistant cells were treated with $5,10,20,40,80$, 120 , and $200 \mu \mathrm{mol} / \mathrm{L}$ cisplatin for $48 \mathrm{~h}$, and the inhibition ratio was measured.

Inhibition ratio assay. The cells were seeded into 96-well plates at a starting density of $2 \times 10^{4}$ cells per well and cultured overnight. Then, various concentrations of drugs were added to the medium for $48 \mathrm{~h}$. The in vitro cell viability effects of cisplatin, Wortmannin, alone, or in combination, were determined by MTT assay. For this assay, we tested two sequences: (a) serial concentrations of cisplatin alone, and (b) serial concentrations of cisplatin plus Wortmannin $(2.5 \mathrm{nmol} / \mathrm{L}$ for A549/DDP, $5 \mathrm{nmol} / \mathrm{L}$ for H460/DDP).

Apoptosis assay. The treatment method of the cell strains in the apoptosis assay is similar to the previously mentioned cell viability assay. In the apoptosis assay, flow detection was measured via the FITC-annexin V/PI binding assay. Analysis was carried out based on flow cytometry (Becman ALTRA, USA), and the results were analyzed using WinMDI 2.9 software.

Detection of caspases-3, caspases- 8 and caspases- 9 activity. The activity of caspase- 3 , caspase- 8 and caspase- 9 were detected using the caspase activity kit (Bio excellence international Tech Co, Ltd). The caspase activity value was determined by detecting the absorbance at $490 \mathrm{~nm}$. Both A549/DDP and H460/DDP cells were collected and lysed in caspase assay buffer, and the supernatant was collected to detect activity.

Western blotting analysis. Following treatment for the cell viability assay, cells were washed twice with PBS and harvested in a chilled lysis buffer $(10 \mathrm{~mm}$ PBS buffer, containing $50 \mathrm{~mm} \mathrm{KCl}, 0.1 \mathrm{~mm}$ PMSF, $0.5 \mathrm{mg} / \mathrm{ml}$ aprotinin, $0.5 \mathrm{mM}$ sodium-metavanadate, $1 \mathrm{mM}$ EDTA, $\mathrm{pH}$ 7.6). Following cell lysis, the total proteins were obtained by centrifugation, and supernatants were adjusted to equal amounts of protein for SDS-PAGE. Separate proteins were electroblotted from SDSPAGE onto PVDF membranes, and then blocked overnight with $5 \%$ nonfat milk powder and $0.1 \%$ Tween 20 in PBS at $4^{\circ} \mathrm{C}$. Afterwards, blots were exposed to a primary antibody for $1 \mathrm{~h}$ at room temperature. After extensive washing with blocking solution, blots were exposed to the appropriate secondary antibody with HRP and detected by an ECL kit (Amersham Pharmacia Biotech).

Statistical analysis. Analysis of densitometry for Western blot was performed by using Image J. Data are presented as means \pm standard deviation (SD). Cell viability assay and apoptosis experiments were performed at least twice with duplicates. For multiple comparisons of groups, ANOVA was used by origin 8.0. Statistical difference between groups was analyzed by unpaired two-tailed Students t-test, Value of $p<$ 0.05 or $p<0.01$ was considered as that there is a discrepancy or significant discrepancy between two groups. 


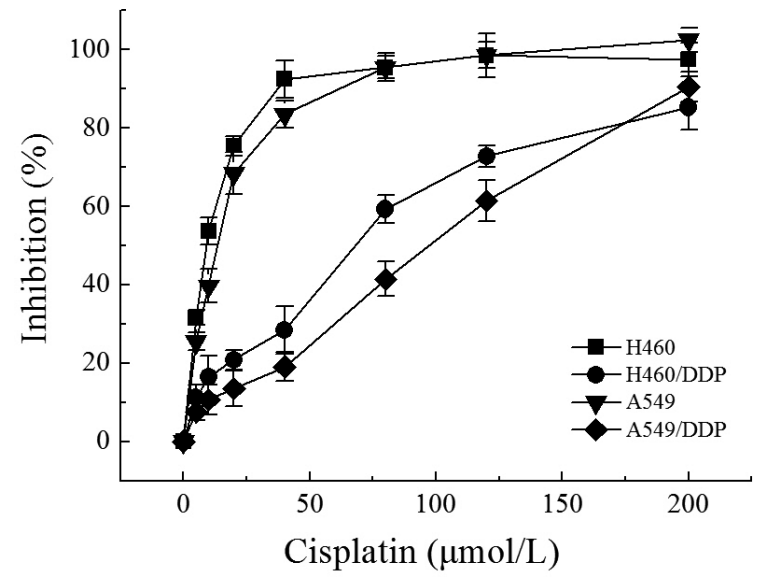

Figure 1. Cisplatin inhibited viability of parental cells (A549 and H460) and cells acquired resistance (A549/DDP and H460/DDP). All cells were exposed to $0,5,10,20,40,80,120$ and $200 \mu \mathrm{mol} / \mathrm{L}$ cisplatin respectively for 48h, A549/DDP, H460/DDP cells appear much more cisplatin tolerance then their parental cell lines. The experiments were repeated thrice. Columns, mean; bars, SD.

A
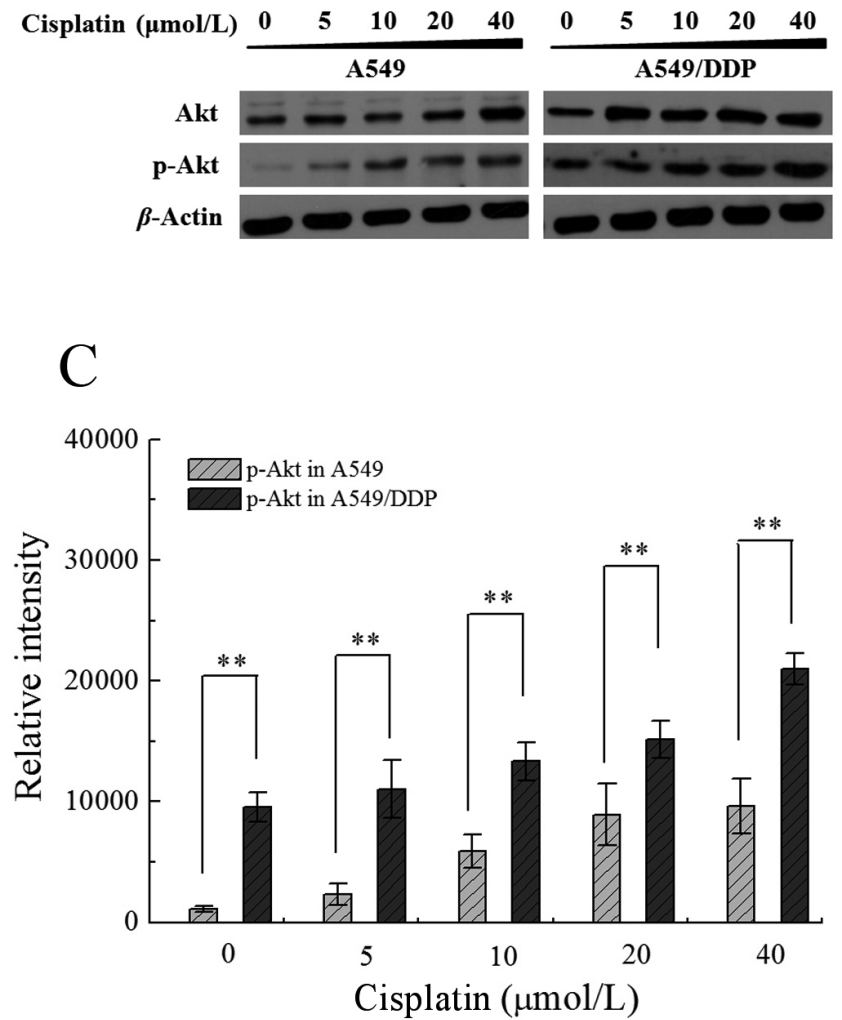

Results

Establishment of cisplatin-resistant cells. As shown in Figure 1, the inhibition ratios of both parental and cisplatin resistant cell strains were increased in a dose-dependent manner, with the parental lung cancer cells, A549 and H460, appearing more sensitive than their resistant variants, A549/DDP and H460/DDP. This suggests that both A549/DDP and H460/ DDP acquired cisplatin-resistance after being continuously exposed to increasing levels of cisplatin for 3 months. The $\mathrm{IC}_{50}$ values for A549/DDP, H460/DDP were 70.7 $\pm 3.5 \mu \mathrm{mol} / \mathrm{L}$ and $53.0 \pm 5.2 \mu \mathrm{mol} / \mathrm{L}$, respectively, a statistically significant difference when compared to A549 and H460 (11.4 $\pm 2.8 \mu \mathrm{mol} / \mathrm{L}$ and $8.8 \pm 1.5 \mu \mathrm{mol} / \mathrm{L}, p<0.01)$. The resistance index for A549/DDP and H460/DDP was 6.2 and 6.0, respectively.

PI3K/Akt pathway in cisplatin resistance. To further determine whether the PI3K/Akt pathway is responsible for cisplatin resistance in A549/DDP and H460/DDP, we analyzed the activation discrepancy of Akt and p-Akt between A549, H460 and cisplatin resistant strains, A549/DDP, H460/DDP

\section{B}
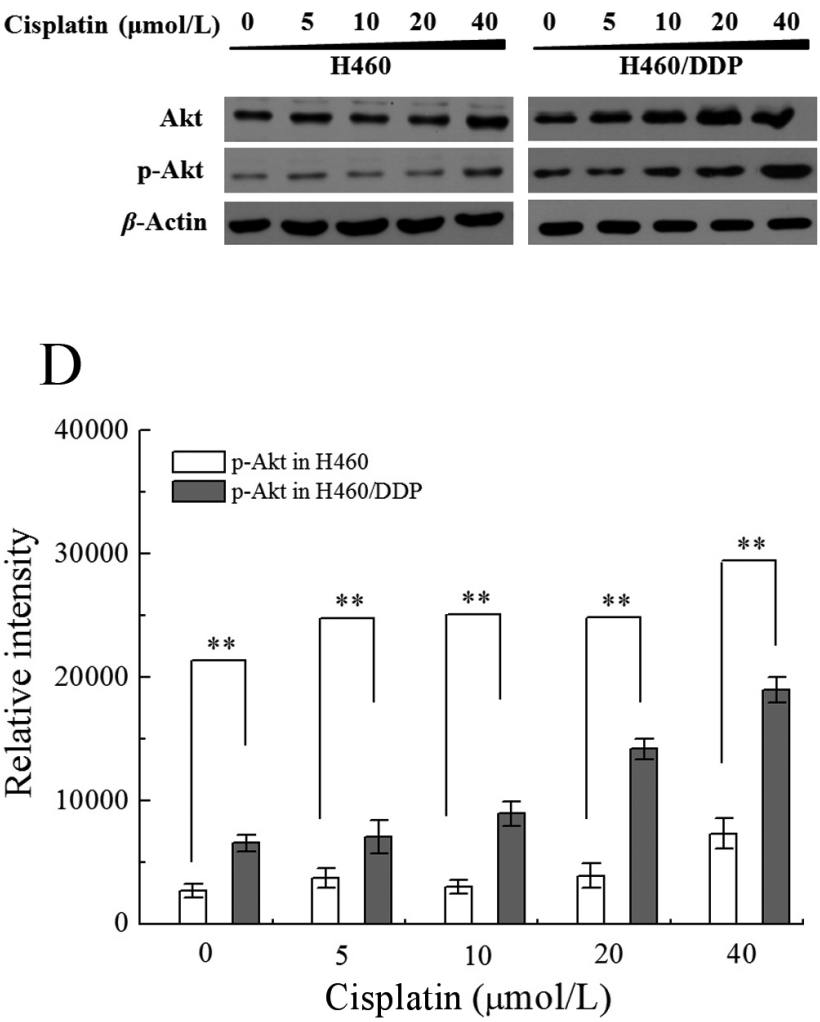

Figure 2. Cisplatin elevated total and phosphorylated Akt in A549/DDP, A549 cell lines, and H460/DDP, H460 cell lines. (A) A549 and A549/DDP cells were exposed to $5,10,20$ and $40 \mu \mathrm{mol} / \mathrm{L}$ cisplatin respectively for $16 \mathrm{~h}$, the change of Akt expression and phosphorylation was displayed by Western Blot assay. (B) Parallel tests were also carried out on H460 and H460/DDP cells like A549 and A549/DDP cells. (C)The discrepancy of Akt expression and phosphorylation between A549/DDP and A549 cells was quantified by histogram. (D) The discrepancy of Akt expression and phosphorylation between H460/DDP and H460 cell strains was quantified by histogram. Relative intensity of each WB lane was analyzed by the image $\mathrm{J} 2 \mathrm{x} 2.1 .4 .7$ soft, The experiments were repeated thrice. Columns, mean; bars, SD. ${ }^{* *} p<0.01$. 
cell lines. Figure 2 shows that a significantly higher level of phosphorylated Akt was detectable in A549/DDP and H460/ DDP cells when compared to their parental cell lines, A549 and $\mathrm{H} 460$. When treated with serial concentrations of cisplatin, the cells strains acquired resistance still exhibited higher level of phosphorylated Akt in a dose-dependent manner when compared to their parental cell lines.

Wortmannin's effect on cisplatin-resistance in A549/ DDP and H460/DDP cell lines. We used a series of concentrations of Wortmannin to identify the minimum concentration required to return phosphorylation level of Akt to their normal range (Figure 3). After analysis, $2.5 \mathrm{nmol} / \mathrm{L}$ and $5.0 \mathrm{nmol} / \mathrm{L}$ Wortmannin were considered the optimum concentrations for the A549/DDP and H460/DDP cell lines, respectively. The results showed that both A549/DDP and
H460/DDP cell lines became more sensitive to cisplatin after Wortmannin treatment, and the mortality rate in the two cell lines dramatically increased (Figure 4). From the growth-inhibitory curves of the cell lines, we observed that the inhibition rate of A549/DDP cells in combination therapy group (90.5\%) was much higher than the monotherapy group $(19.1 \%)$ when both of them were treated with $40 \mu \mathrm{mol} / \mathrm{L}$ cisplatin, and a similar phenomenon also occurred in $\mathrm{H} 460$ / DDP cells (inhibition rate increased from $28.5 \%$ to $96.3 \%$ ). The $\mathrm{IC}_{50}$ values of cisplatin for A549/DDP and H460/DDP cell lines were $9.4 \pm 2.1 \mu \mathrm{mol} / \mathrm{L}$ and $9.0 \pm 1.3 \mu \mathrm{mol} / \mathrm{L}$, respectively, in the Wortmannin combination therapy group, compared with $70.7 \pm 3.5 \mu \mathrm{mol} / \mathrm{L}$ and $53.0 \pm 5.2 \mu \mathrm{mol} / \mathrm{L}$ for A549/DDP and H460/DDP cell lines, respectively, in the monotherapy group $(p<0.01)$.
A

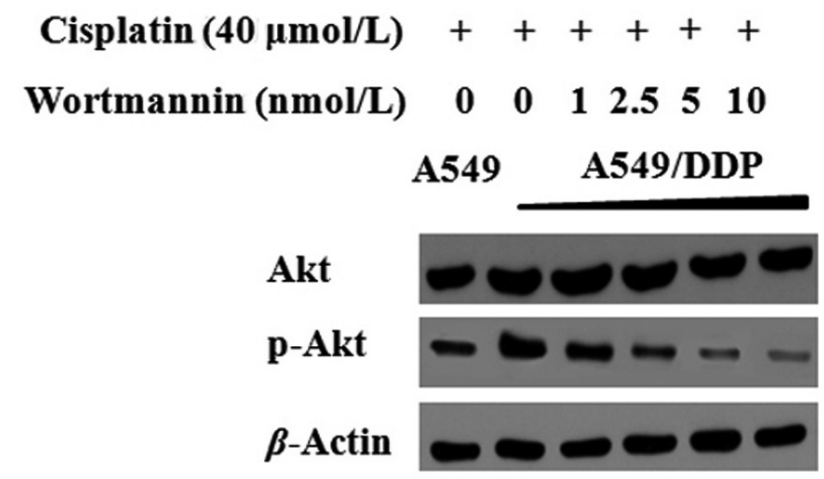

B

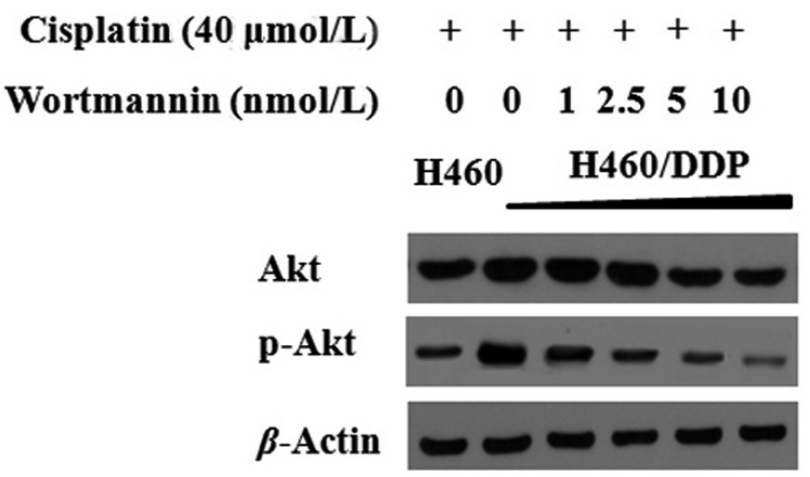

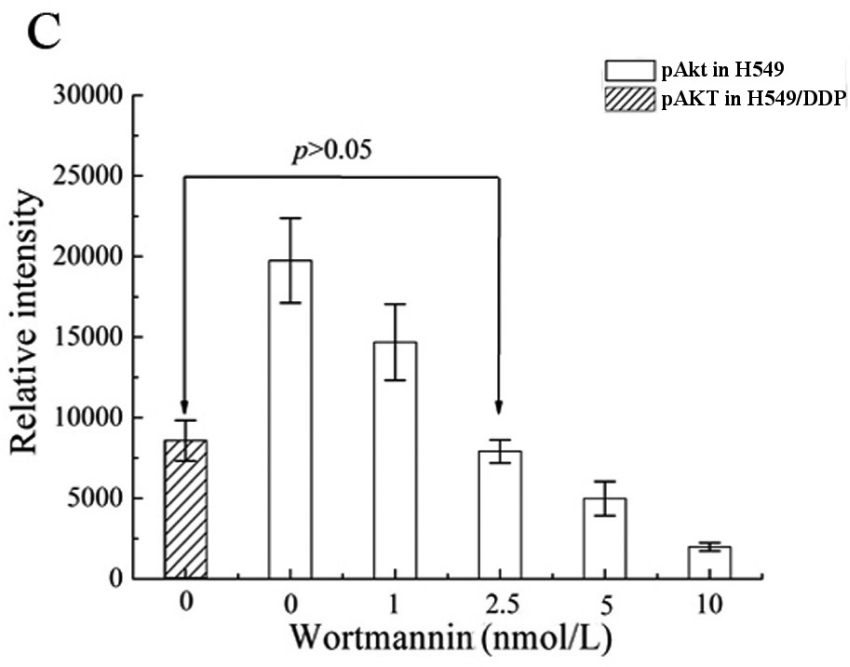

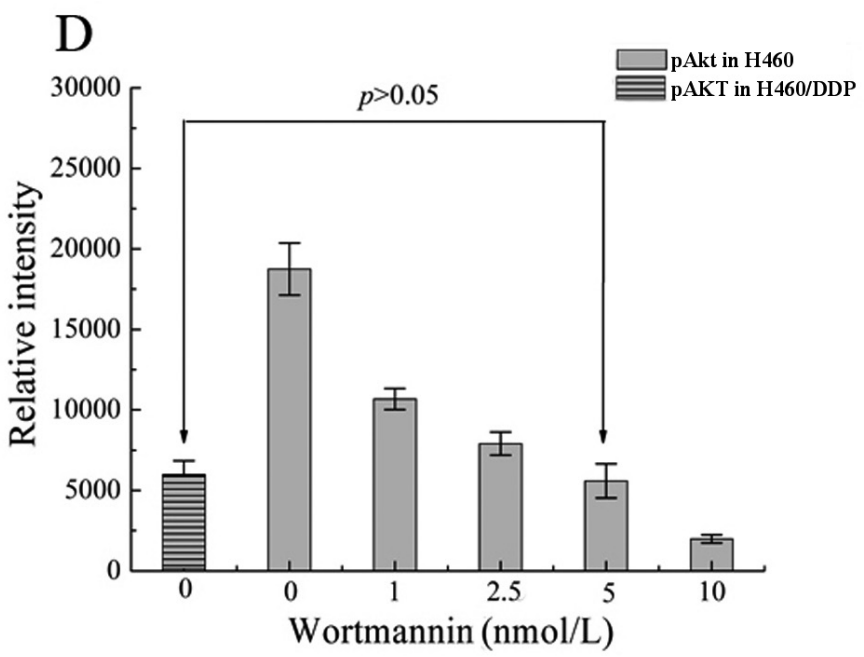

Figure 3. Cisplatin-stimulated Akt activity could be inhibited by Wortmannin. (A) A549 and A549/DDP cells were pre-treated with $40 \mu \mathrm{mol} / \mathrm{L}$ cisplatin, followed by the addition of 1,2.5,5,10 nmol/L Wortmannin, respectively, and cultivated for $16 \mathrm{~h}$. Then, phosphorylation levels of Akt were visualized by Western Blot. (B) Parallel probes were also carried out on H460 and H460/DDP cells like A549 and A549/DDP cells. (C)The detailed phosphorylation differences between A549 and A549/DDP cells were showed by gray histogram. (D) The detailed phosphorylation differences between A549 and A549/ DDP cells were showed by gray histogram. The relative intensity of each WB lane was analyzed by the image $\mathrm{J} 2 \mathrm{x} 2.1$.4.7 soft. The proper concentrations for next experiments were selected by the standard phosphorylation level of Akt in cells have not statistically significant between parental and cisplatin resistant cell lines $(p>0.05)$. 


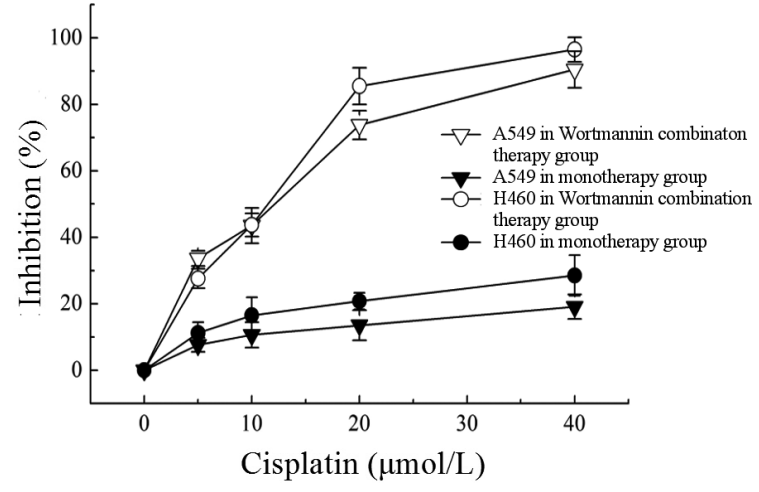

Figure 4. Wortmannin reverses the cisplatin resistance and enhances mortality rate on both A549/DDP and H460/DDP cells which were measured by MTT assay. All cells were exposed to $5,10,20$ and $40 \mu \mathrm{mol} / \mathrm{L}$ cisplatin or together with Wortmannin $(2.5 \mathrm{nmol} / \mathrm{L}$ for A549, $5 \mathrm{nmol} / \mathrm{L}$ for $\mathrm{H} 460)$ respectively for 48h, A549/DDP and H460/DDP cells which in the Wortmannin combination therapy group appear less cisplatin tolerance then the others in the monotherapy group. The experiments were repeated quintic. Columns, mean; bars, SD.
Wortmannin enhances apoptosis-promoting effect of cisplatin in A549/DDP and H460/DDP cell lines. Annexin V/PI-positive cells were markedly increased in the combination treatment group for both A549/DDP and H460/DDP cell lines when compared to monotherapy group (Figure 5). With a concentration of cisplatin of $40 \mu \mathrm{mol} / \mathrm{L}$, the apoptotic rate of the combination treatment group (A549/DDP cell line, 79.2\% and H460/DDP cell line, 75.7\%) was significantly higher than the monotherapy group (A549/DDP cell line, 39.5\% and H460/DDP cell line, $36.6 \%$ ). In order to gain further insight into the molecular mechanism about how Wortmannin promotes the apoptosis effect of cisplatin, we examined caspase activity of apoptosis proteins caspase- 3 , caspase- 8 , and caspase- 9 . In the monotherapy group, the caspase- 3 , caspase- 8 , and caspase- 9 enzyme activity in both A549/DDP and H460/DDP cells were significantly enhanced after exposure to Wortmannin (2.5 nmol/L for A549/ DDP, $5 \mathrm{nmol} / \mathrm{L}$ for H460/DDP) (Figure 6).

Wortmannin's effect on cisplatin-resistance via PI3K/Akt pathway. The phosphorylation level of BAD and expression

\section{A}

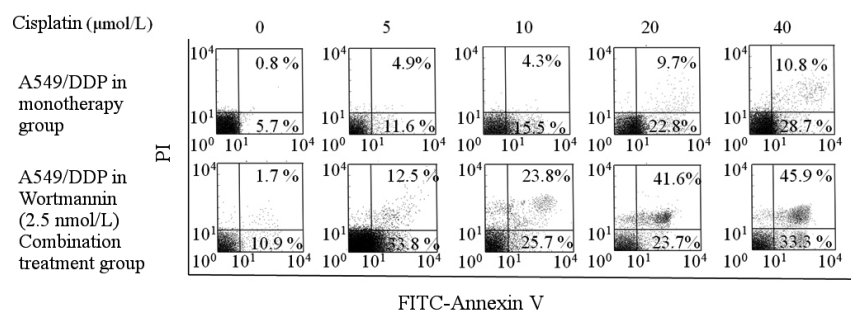

B

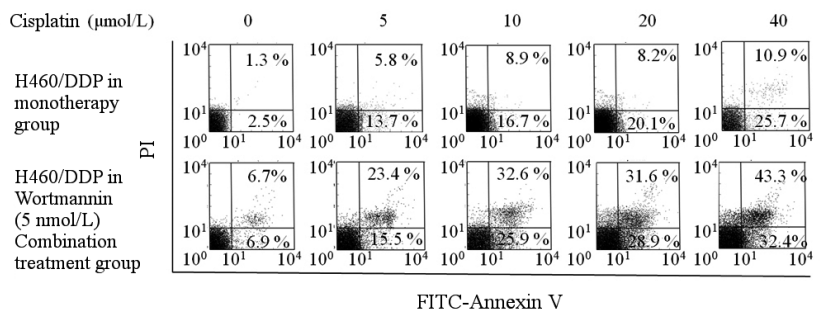

$\mathrm{D}$
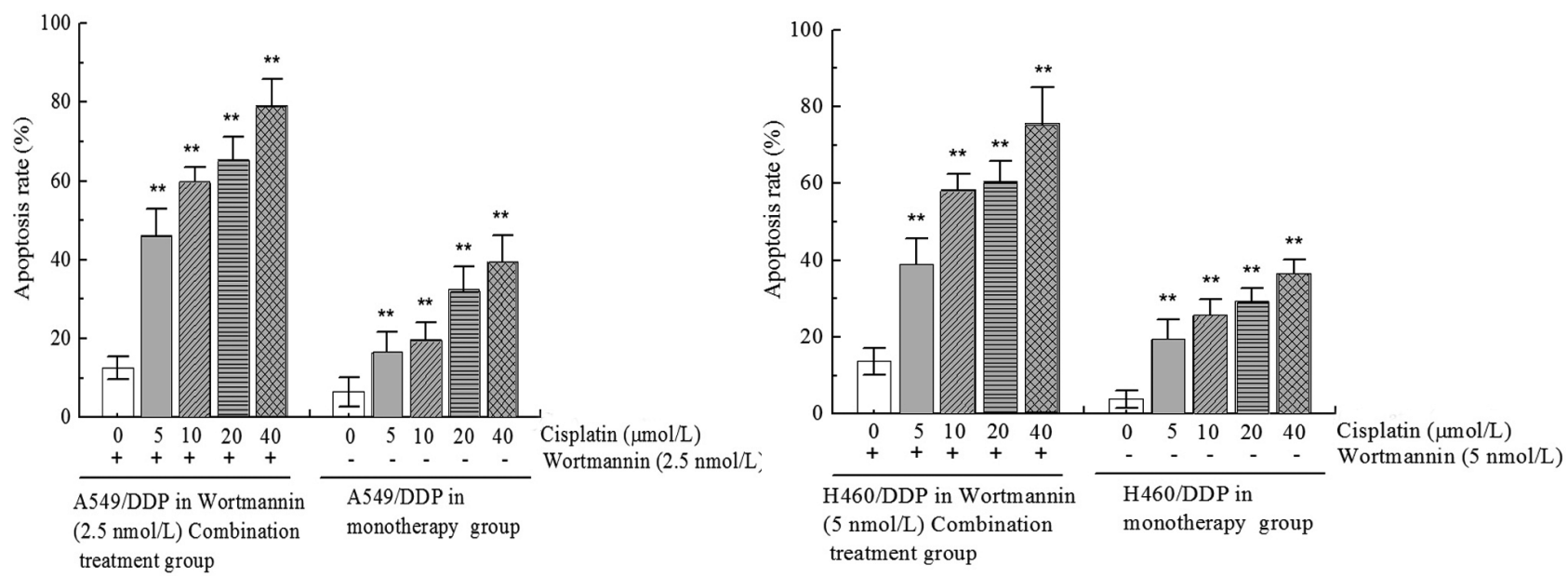

Figure.5 Representative apoptosis analyses for enhancing apoptosis effect of Wortmannin on A549/DDP and H460/DDP cells in cisplatin therapy. (A) A549 and A549/DDP cells were exposed to 5,10,20 and $40 \mu \mathrm{mol} / \mathrm{L}$ cisplatin alone or together with $2.5 \mathrm{nmol} / \mathrm{L}$ Wortmannin respectively, cells were harvested at $48 \mathrm{~h}$ and stained with Annexin-V-fluorescein isothiocyanate (FITC) and propidium iodide (PI) followed by FACScan flow cytometric analysis. (B) To observe whether Wortmannin could enhance apoptosis effect on H460/DDP cells or not, parallel experiments were also carried out on H460 and H460/DDP cells. (C) The apoptosis rate of A549 and A549/DDP cells were showed by gray histogram which calculated by Becman ALTRA soft. (D) Apoptosis rate histogram of $\mathrm{H} 460$ and $\mathrm{H} 460$ /DDP cells, FITC-Annexin V positive population was deemed as the valid apoptosis rate in this experiment. The experiments were repeated quintic. Columns, mean; bars, SD. ${ }^{*} p<0.05$ and ${ }^{* *} p<0.01$. 
A

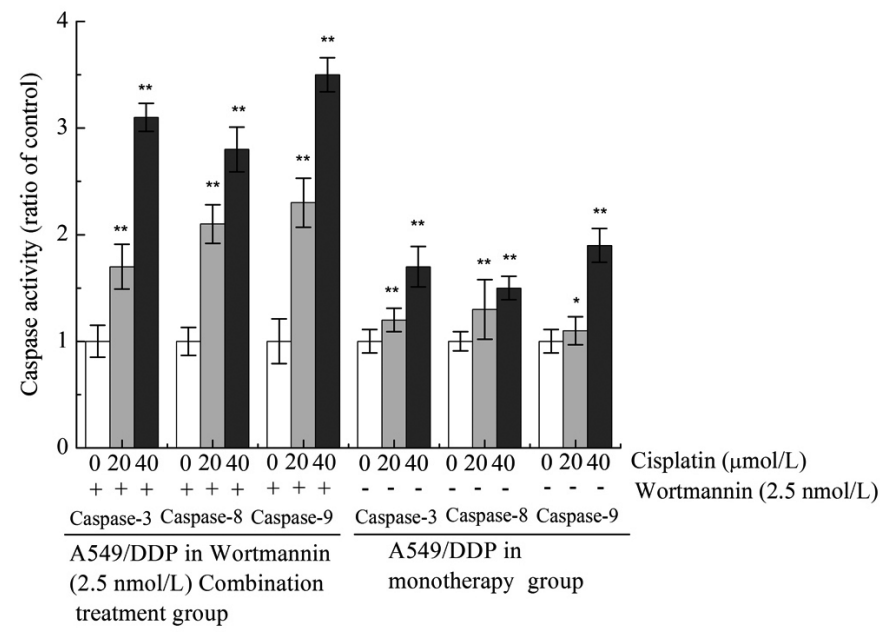

B

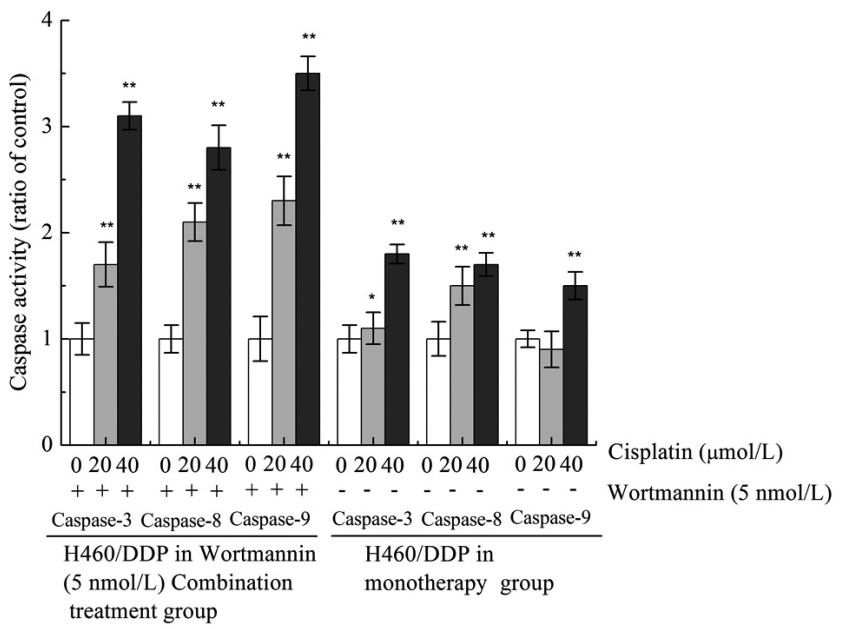

Figure 6. Effect of Wortmannin on cisplatin-induced caspase-3, Caspase-8 and Caspase-9 activation in lung cancer cell lines. (A)A549 and A549/DDP cells were exposed to $2.5 \mathrm{nmol} / \mathrm{L}$ Wortmannin alone (empty bars), or together with $20 \mu \mathrm{mol} / \mathrm{L}$ of cisplatin (gray bars), $40 \mu \mathrm{mol} / \mathrm{L}$ of cisplatin (black bars) for $16 \mathrm{~h}$. (B) $\mathrm{H} 460$ and H460/DDP cells were exposed to $5 \mathrm{nmol} / \mathrm{L}$ Wortmannin alone (empty bars), or together with 20 $\mu \mathrm{mol} / \mathrm{L}$ of cisplatin (gray bars), $40 \mu \mathrm{mol} / \mathrm{L}$ of cisplatin (black bars) for $16 \mathrm{~h}$. Caspase-3, Caspase-8, and Caspase-9 were measured by colorimetric assay as described above, and the result were showed by histogram. The experiments were repeated quintic. Columns, mean; bars, SD. ${ }^{\star} p<0.05$ and ${ }^{* *} p<0.01$.

level of Bcl-2 and Bax proteins were detected by Westernblot assay(Figure 7). In the monotherapy group, cisplatin caused apparent phosphorylation of Akt in A549/DDP cells, and increased phosphorylation of BAD. In contrast to the control group, Wortmannin prevented the phosphorylation level of Akt induced by cisplatin in the combined treatment group. Also in contrast to the control group, the expression level of Bax was significantly

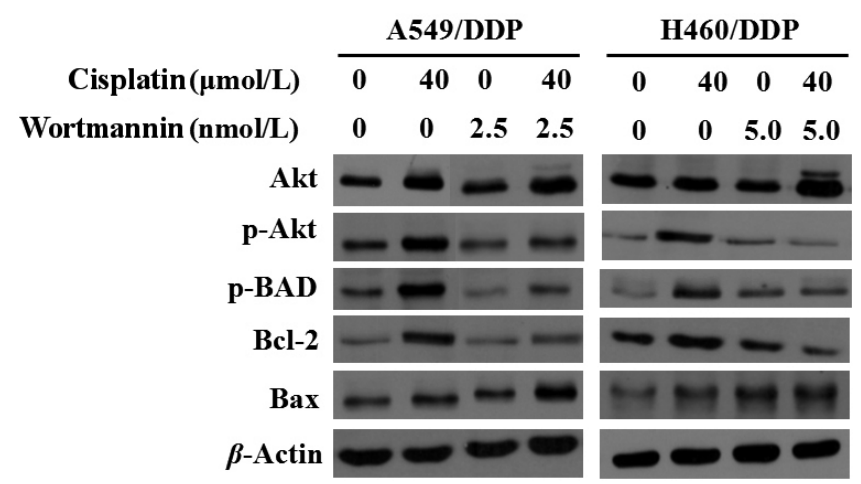

Figure 7. Promote the apoptosis pathway by Wortmannin. Bcl-2 degradation, decreasing of $\mathrm{BAD}$ phosphorylation and increasing of Bax expression are detected in A549/DDP and H460/DDP cells by Western blot assay. A549/DDP and H460/DDP cells were cultivated in RPMI-1640 for $16 \mathrm{~h}$ with or without $40 \mu \mathrm{mol} / \mathrm{L}$ cisplatin, $2.5 \mathrm{nmol} / \mathrm{L}$ and $5.0 \mathrm{nmol} / \mathrm{L}$ Wortmannin were added into the A549/DDP cells and H460/DDP cells respectively. Data are representative of three independent experiments. increased, while the expression level of Bcl-2 was decreased. Similar results were also obtained in H460/DDP cells.

Previous research has verified that a multimer of Bax is a one of triggers in the mitochondrial apoptosis pathway[19, 20]. Increased expression of Bax often contributes to extracellular release of Cytochrome $\mathrm{C}$ from mitochondria to cytosol. After treatment with Wortmannin for $48 \mathrm{~h}$, there was increased accumulation of Cytochrome $\mathrm{C}$ in the cytosol when compared

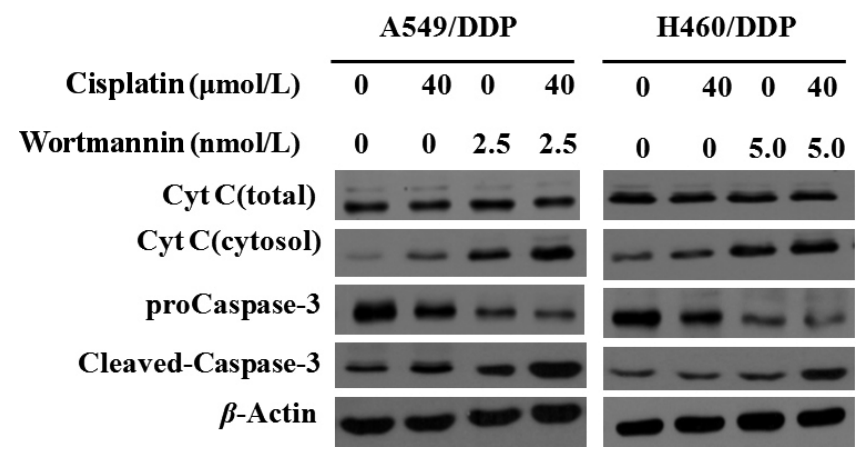

Figure 8. Effect of PI3K inhibitor Wortmannin on cisplatin-induced cytochrome c release in A549/DDP and H460/DDP cells. A549/DDP and H460/ DDP cells were exposed to $40 \mu \mathrm{mol} / \mathrm{L}$ of cisplatin alone, or together with $2.5 \mathrm{nmol} / \mathrm{L}$ of Wortmannin, $5 \mathrm{nmol} / \mathrm{L}$ of Wortmannin for A549/DDP and $\mathrm{H} 460 / \mathrm{DDP}$ cells respectively for $16 \mathrm{~h}$. After subcellular fractionation, the cytosolic fraction of the cells was used for determination of cytochrome c release by western blot assay. The experiments were repeated thrice. Columns, mean; bars, SD. 
to the control, in both A549/DDP and H460/DDP cell lines (Figure 8).

\section{Discussion}

Cisplatin-based chemotherapy is still the first line therapeutic treatment in lung cancer therapy. However, the emergence of resistance to chemotherapy has become a chief obstacle in effective cancer treatment. During the course of cisplatin therapy, there is a balance between survival and apoptotic signals, and a tilt towards the former directly contributes to cisplatin-resistance by these lung cancer cells. Akt was originally identified as the oncogene in the transforming retrovirus in 1977, and its role in regulating apoptosis has been identified[21]. Akt conveys pro-survival signals by phosphorylating and inactivating pro-apoptotic proteins, as well as downregulating the transcription of several pro-apoptotic genes[22-24]. Extensive studies in previous years focusing on the PI3K/Aktpathway have identified the crucial correlation between this pathway and chemoresistance in various human cancers $[25,26]$. The occurrence of chemoresistance is often attributed to the abnormal activity of apoptosis-related proteins such as BAD, Bcl-xL and the caspase family. BAD could be activated by Akt, and their relationship suggests that the PI3K/Aktpathway could be a useful target in overcoming cisplatin resistance.

However, the PI3K/Aktpathway's role in drug resistance and the underlying mechanism between these apoptosisrelated proteins in human lung cancer remains unclear. To better understand the underlying mechanism of cisplatin resistance, we induced cisplatin resistance in human lung cancer cells. In our study, H460 cells were more sensitive to cisplatin-induced cytotoxicity than A549 cells, but similarly, hyperphosphorylation of Akt has been detected in both A549 and H460 cells when two cell lines acquire chemoresistance, indicating that cisplatin stimulates the PI3K/Aktpathway.

We found that in lower doses, Wortmannin, introduced as a specific inhibitor of PI3Ks, directly downregulated the phosphorylation level of Akt, significantly reversing cisplatinresistance. Both A549/DDP and H460/DDP cell lines became more sensitive to cisplatin when compared to the monothrepy group which treated with cisplatin alone. Furthermore, a similar phenomenon was also observed in our apoptosis assay, suggesting that downregulation of hyperphosphorylation of Akt is an effective method of reversing the resistance of lung cancer cells to cisplatin, and re-sensitizing those cells to cisplatin-induced apoptosis. Accordingly, the similar research in earlier study Larisa L. Belyanskaya et al. [27] also gave our result a forceful support, Activated Akt could protected SCLC cells against cisplatin -induced apoptosis, whereas dominant negative Akt increased the cells sen-sitivity to cisplatin.

$\mathrm{BAD}$ is a pro-apoptotic protein of the $\mathrm{Bcl}-2$ family involved in initiating apoptosis and other various components of chemotherapeutic resistance via the PI3K/Akt pathway[28]. We observed a similar trend, as stimulation of A549/DDP and
H460/DDP cell lines with serial concentrations of cisplatin resulted in $\mathrm{BAD}$ activation via phosphorylation. It has been mentioned in several reports that the BAD-induced apoptosis pathway could be activated via Ser 136 phosphorylation by Akt, and once activated, BAD will dissociate from the Bcl-2/Bcl-X complex, losing its pro-apoptotic function [29-31]. Then, the isolated Bcl-2 further prevents Bax from inserting into the mitochondrial membrane by disturbing Bid-induced Bax oligomerization [32,33]. Bax oligomerization induces apoptosis by way of Cytochrome $\mathrm{C}$ release in the mitochondria [34, 35]. Once released, cytochrome c cooperates with apoptotic protease-activating factor-1 (Apaf-1) and induces caspase-9 activation, which is directly involved in the activation of executioner caspase-3[36]. Caspase-3 acts as a key executor in apoptosis and plays an important role in programmed cell death. Finally, activated caspase- 3 causes DNA breakage, initiating cell apoptosis [37]. Because Bax oligomerization is an essential part of the Cytochrome $\mathrm{C}$ channel in the mitochondrial membrane $[38,39]$, the inhibition of Bax multimer formation plays a vital role in apoptotic resistance. In our study, we first proved that Wortmannin could increase the activation of caspase- 3 , caspase- 8 , and caspase- 9 through the inhibition of the PI3K/Aktpath way, activating BAD and Cytochrome $\mathrm{C}$ release, confirming that cisplatin resistance is closely linked to caspase-dependent apoptosis and the PI3K/Aktpathway.

In conclusion, our data reveals that Wortmannin can induce both A549/DDP and H460/DDP cell lines to become more sensitive to cisplatin in vitro, We first found that its reversal mechanism of cisplatin-resistance: Wortmannin is able to devitalize the proapototic caspase adapter protein-BAD and launch the cascade reaction of caspase via PI3K/Akt pathway, then, the cascade reaction of caspase initiate the Cytochrome $\mathrm{C}$ release in the mitochondria which is the direct reason for reversion of cisplatin resistance. The present study demonstrates that PI3K/ Akt plays a crucial role in the cisplatin resistance in human lung cancer cells. Cancer cells' loss of PI3K activity facilitates apoptosis and recovers the sensitivity of cells to cisplatin. In summary, the results of the current study support PI3K/Akt as a valid therapeutic target and strongly suggest that PI3K/Akt inhibitors used in conjunction with conventional chemotherapy may be a potentially useful therapeutic strategy in treating lung cancer patients.

\section{References}

[1] BESSE B, RECK M. Pharmacogenomics in NSCLC: mostly unsexy but desperately needed. Ann Oncol 2014; 25: 2099-100. http://dx.doi.org/10.1093/annonc/mdu289

[2] BRONTE G, LO VULlO F, PERNICE G, GALVANO A, FIORENTINO E, ET AL. Farletuzumab for NSCLC: exploiting a well-known metabolic pathway for a new therapeutic strategy. Expert Opin Investig Drugs 2014; 24: 125-32. http:// dx.doi.org/10.1517/13543784.2015.979284

[3] PETERS S, ADJEI AA. Lung cancer. How much platinum-based chemotherapy is enough in NSCLC? Nat Rev 
Clin Oncol 2014; 12: 8-10. http://dx.doi.org/10.1038/ nrclinonc.2014.212

[4] BLANCO VM, LATIF T, CHU Z, QI X. Imaging and Therapy of Pancreatic Cancer with Phosphatidylserine-Targeted Nanovesicles. Transl Oncol 2015; 8: 196-203. http://dx.doi. org/10.1016/j.tranon.2015.03.011

[5] DEVILLIER R, RAFFOUX E, REY J, LENGLINE E, RONCHETTI AM, et al. Combination therapy with ruxolitinib plus intensive treatment strategy is feasible in patients with blast-phase myeloproliferative neoplasms. Br J Haematol 2015.

[6] MAGNUSSEN GI, EMILSEN E, GILLER FLETEN K, ENGESAETER B, NAHSE-KUMPF V, et al. Combined inhibition of the cell cycle related proteins Weel and Chk1/2 induces synergistic anti-cancer effect in melanoma. BMC Cancer 2015; 15: 462. http://dx.doi.org/10.1186/s12885-015-1474-8

[7] HEAVEY S, O'BYRNE KJ, GATELY K. Strategies for cotargeting the PI3K/AKT/mTOR pathway in NSCLC. Cancer Treat Rev 2013; 40: 445-56. http://dx.doi.org/10.1016/j. ctrv.2013.08.006

[8] LIU Y, YANG H, CHEN T, LUO Y, XU Z, et al. Silencing of Receptor Tyrosine Kinase ROR1 Inhibits Tumor-Cell Proliferation via PI3K/AKT/mTOR Signaling Pathway in Lung Adenocarcinoma. PLoS One 2015; 10: e0127092. http://dx.doi. org/10.1371/journal.pone.0127092

[9] MAKINOSHIMA H, TAKITA M, SARUWATARI K, UMEMURA S, OBATA Y, et al. Signaling through the Phosphatidylinositol 3-Kinase (PI3K)/ Mammalian Target of Rapamycin (mTOR) Axis is Responsible for Aerobic Glycolysis mediated by Glucose Transporter in Epidermal Growth Factor Receptor (EGFR)-mutated Lung Adenocarcinoma. J Biol Chem 2015. http://dx.doi.org/10.1074/jbc. M115.660498

[10] WEN XP, MA HL, ZHAO LY, ZHANG W, DANG CX. MiR30a suppresses non-small cell lung cancer progression through AKT signaling pathway by targeting IGF1R. Cell Mol Biol (Noisy-le-grand) 2015; 61: 78-85.

[11] SACCO PC, MAIONE P, ROSSI A, BARECSHINO MA, SGAMBATO A, et al. The PI3k inhibitors: new hopes in the battle against advanced NSCLC. Front Biosci (Landmark Ed) 2014; 19: 259-71. http://dx.doi.org/10.2741/4205

[12] PELTIER J, O`NEILL A, SCHAFFER DV. PI3K/Akt and CREB regulate adult neural hippocampal progenitor proliferation and differentiation. Dev Neurobiol 2007; 67: 1348-61. http://dx.doi.org/10.1002/dneu.20506

[13] TROCA-MARIN JA, CASANAS JJ, BENITO I, MONTESINOS ML. The Akt-mTOR pathway in Down's syndrome: the potential use of rapamycin/rapalogs for treating cognitive deficits. CNS Neurol Disord Drug Targets 2013; 13: 34-40. http://dx.doi.org/10.2174/18715273113126660184

[14] BORONKAI A, BELLYEI S, SZIGETI A, POZSGAI E, BOGNAR Z, et al. Potentiation of paclitaxel-induced apoptosis by galectin-13 overexpression via activation of Ask-1-p38-MAP kinase and JNK/SAPK pathways and suppression of Akt and ERK1/2 activation in U-937 human macrophage cells. Eur J Cell Biol 2009; 88: 753-63. http://dx.doi.org/10.1016/j. ejcb.2009.07.005
[15] LI SS, TANG QL, WANG SH, CHEN YH, LIU JJ, et al. Simultaneously targeting Bcl-2 and Akt pathways reverses resistance of nasopharyngeal carcinoma to TRAIL synergistically. Tumori 2012; 97: 762-70.

[16] GU L, FINDLEY HW, ZHU N, ZHOU M. Endogenous TNFalpha mediates cell survival and chemotherapy resistance by activating the PI3K/Akt pathway in acute lymphoblastic leukemia cells. Leukemia 2006; 20: 900-4. http://dx.doi. org/10.1038/sj.leu.2404160

[17] ZHANG W, CAI J, CHEN S, ZHENG X, HU S, et al. Paclitaxel resistance in MCF-7/PTX cells is reversed by paeonol through suppression of the SET/phosphatidylinositol 3-kinase/Akt pathway. Mol Med Rep 2015; 12: 1506-14. http://dx.doi. org $/ 10.3892 / \mathrm{mmr} .2015 .3468$

[18] WU G, QIN XQ, GUO JJ, LI TY, CHEN JH. AKT/ERK activation is associated with gastric cancer cell resistance to paclitaxel. Int J Clin Exp Pathol 2014; 7: 1449-58.

[19] SCHULER M, MAURER U, GOLDSTEIN JC, BREITENBUCHER F, HOFFARTH S, et al. p53 triggers apoptosis in oncogene-expressing fibroblasts by the induction of Noxa and mitochondrial Bax translocation. Cell Death Differ 2003; 10: 451-60. http://dx.doi.org/10.1038/sj.cdd.4401180

[20] KUMAR MA, NAIR M, HEMA PS, MOHAN J, SANTHOSHKUMAR TR. Pinocembrin triggers Bax-dependent mitochondrial apoptosis in colon cancer cells. Mol Carcinog 2007; 46: 231-41. http://dx.doi.org/10.1002/mc.20272

[21] STAAL SP, HARTLEY JW, ROWE WP. Isolation of transforming murine leukemia viruses from mice with a high incidence of spontaneous lymphoma. Proc Natl Acad Sci U S A 1977; 74: 3065-77. http://dx.doi.org/10.1073/pnas.74.7.3065

[22] PAN ST, QIN Y, ZHOU ZW, HE ZX, ZHANG X, et al. Plumbagin induces $\mathrm{G} 2 / \mathrm{M}$ arrest, apoptosis, and autophagy via p38 MAPK- and PI3K/Akt/mTOR-mediated pathways in human tongue squamous cell carcinoma cells. Drug Des Devel Ther 2015; 9: 1601-26.

[23] GURU SK, PATHANIA AS, KUMAR S, RAMESH D, KUMAR M, et al. Secalonic acid-D represses HIF-1alpha/ VEGF mediated angiogenesis by regulating the Akt/mTOR/ p70S6K signaling cascade. Cancer Res 2015. http://dx.doi. org/10.1158/0008-5472.CAN-14-2312

[24] CAO L, DUANMU W, YIN Y, ZHOU Z, GE H, et al. Dihydroartemisinin exhibits anti-glioma stem cell activity through inhibiting p-AKT and activating caspase-3. Pharmazie 2015; 69: $752-8$.

[25] YU HG, AI YW, YU LL, ZHOU XD, LIU J, et al. Phosphoinositide 3-kinase/Akt pathway plays an important role in chemoresistance of gastric cancer cells against etoposide and doxorubicin induced cell death. Int J Cancer 2008; 122: 433-43. http://dx.doi.org/10.1002/ijc.23049

[26] YANG X, FRASER M, MOLL UM, BASAK A, TSANG BK. Akt-mediated cisplatin resistance in ovarian cancer: modulation of p53 action on caspase-dependent mitochondrial death pathway. Cancer Res 2006; 66: 3126-36. http://dx.doi. org/10.1158/0008-5472.CAN-05-0425

[27] BELYANSKAYA LL, HOPKINS-DONALDSON S, KURTZ S, SIMOES-WUST AP, YOUSEFI S, et al. cisplatin activates Akt in small cell lung cancer cells and attenuates apoptosis by 
survivin upregulation. Int J Cancer 2005; 117: 755-63. http:// dx.doi.org/10.1002/ijc.21242

[28] SHE QB, SOLIT DB, YE Q, O‘REILLY KE, LOBO J, et al. The $\mathrm{BAD}$ protein integrates survival signaling by EGFR/MAPK and PI3K/Akt kinase pathways in PTEN-deficient tumor cells. Cancer Cell 2005; 8: 287-97. http://dx.doi.org/10.1016/j. ccr.2005.09.006

[29] SAKAMAKI J, DAITOKU H, UENO K, HAGIWARA A, YAMAGATA K, et al. Arginine methylation of BCL-2 antagonist of cell death (BAD) counteracts its phosphorylation and inactivation by Akt. Proc Natl Acad Sci U S A 2011; 108: 6085-90. http://dx.doi.org/10.1073/pnas.1015328108

[30] BLUME-JENSEN P, JANKNECHT R, HUNTER T. The kit receptor promotes cell survival via activation of PI 3-kinase and subsequent Akt-mediated phosphorylation of $\mathrm{Bad}$ on Ser136. Curr Biol 1998; 8: 779-82. http://dx.doi.org/10.1016/ S0960-9822(98)70302-1

[31] CONDORELli F, SALOMONI P, COTTERET S, CESI V, SRINIVASULA SM, et al. Caspase cleavage enhances the apoptosis-inducing effects of BAD. Mol Cell Biol 2001; 21: 3025-36. http://dx.doi.org/10.1128/MCB.21.9.3025$\underline{3036.2001}$

[32] CARLONI S, BUONOCORE G, LONGINI M, PROIETTI F, BALDUINI W. Inhibition of rapamycin-induced autophagy causes necrotic cell death associated with Bax/Bad mitochondrial translocation. Neuroscience 2012; 203: 160-9. http:// dx.doi.org/10.1016/j.neuroscience.2011.12.021

[33] BARREZUETA LF, OSHIMA CT, LIMA FO, DE OLIVEIRA COSTA H, GOMES TS, et al. The intrinsic apoptotic signaling pathway in gastric adenocarcinomas of Brazilian patients:
Immunoexpression of the Bcl-2 family (Bcl-2, Bcl-x, Bak, Bax, Bad) determined by tissue microarray analysis. Mol Med Rep 2011; 3: 261-7.

[34] MORALES-CRUZ M, FIGUEROA CM, GONZALEZROBLES T, DELGADO Y, MOLINA A, et al. Activation of caspase-dependent apoptosis by intracellular delivery of Cytochrome c-based nanoparticles. J Nanobiotechnology 2014; 12: 33. http://dx.doi.org/10.1186/s12951-014-0033-9

[35] ZHAO J, WANG J, WU J. Roles of cytochrome c, caspase-9, and caspase- 3 in pentavalent vanadium-induced neuronal apoptosis. Zhonghua Lao Dong Wei Sheng Zhi Ye Bing Za Zhi 2014; 32: 664-7.

[36] LI P, NIJHAWAN D, WANG X. Mitochondrial activation of apoptosis. Cell 2004; 116: S57-9, 2 p following S9.

[37] MALEKINEJAD H, MORADI M, FINK-GREMMELS J. Cytochrome C and Caspase-3/7 are Involved in Mycophenolic Acid- Induced Apoptosis in Genetically Engineered PC12 Neuronal Cells Expressing the p53 gene. Iran J Pharm Res 2014; 13: 191-8.

[38] GEORGE NM, TARGY N, EVANS JJ, ZHANG L, LUO $\mathrm{X}$. Bax contains two functional mitochondrial targeting sequences and translocates to mitochondria in a conformational change- and homo-oligomerization-driven process. J Biol Chem 2009; 285: 1384-92. http://dx.doi.org/10.1074/ jbc.M109.049924

[39] MIKHAILOV V, MIKHAILOVA M, PULKRABEK DJ, DONG Z, VENKATACHALAM MA, et al. Bcl-2 prevents Bax oligomerization in the mitochondrial outer membrane. J Biol Chem 2001; 276: 18361-74. http://dx.doi.org/10.1074/ jbc.M100655200 